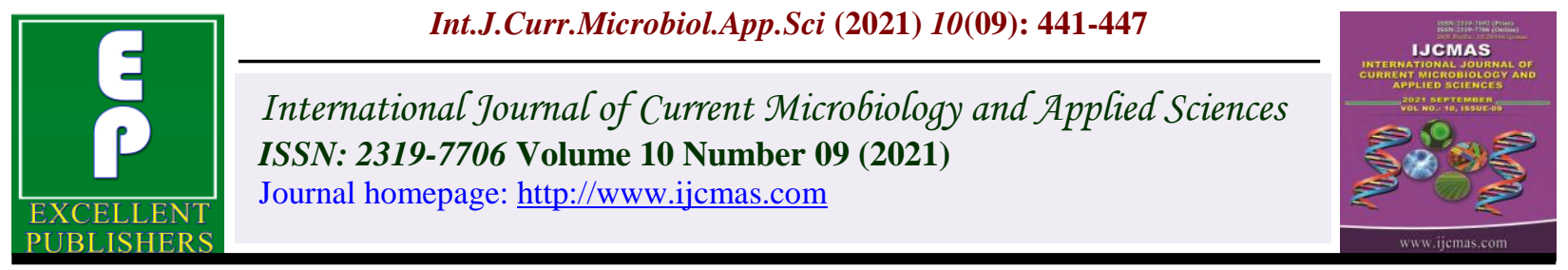

\title{
Comparison of Major Biological Characteristics and Adaptations of three Sand Pear Varieties in Hubei Province of China
}

\author{
Tian-Zhi Gong, Feng Xu and Guiyuan Wang*
}

Yangtze University, College of Horticulture and Gardening, Jingzhou, Hubei 434020, China

*Corresponding author

\section{A B S T R A C T}

Keywords

Yuan Huang;

Cui Guan; Chang Li

No.1'; Growth

characteristics;

Adaptability

Article Info

Accepted:

15 August 2021

Available Online:

10 September 2021
The growth performance and adaptability of 'Chang Li No.1', 'Cui Guan' and 'Yuan Huang' after their planted in the first and third years were investigated. The results showed that:(1) The first year after the bud seedling planted, in plant height aspect, 'Yuan Huang' was the highest about $164.4 \mathrm{~cm}$, 'Cui Guan' was the lowest about $116.4 \mathrm{~cm}$; in leaf number aspect, 'Chang Li No.1' was the least about 11, 'Cui Guan' and 'Yuan Huang' were equivalent; in rate of survival, the survival rate of 'Chang Li No.1' was the highest about $82.4 \%$, however, the survival rate of 'Cui Guan' and 'Yuan Huang' were $64.9 \%$ and $62.1 \%$ respectively; (2) The third year after planted, in plant height aspect, 'Yuan Huang' was the highest about 3.46 m, 'Cui Guan' and 'Chang Li No.1' were $2.72 \mathrm{~m}$ and $2.65 \mathrm{~m}$ respectively; in crown diameter aspect, 'Yuan Huang' was the largest, 'Cui Guan' and 'Chang Li No.1' were equivalent; (3) In the number of annual branches, 'Yuan Huang' was the largest whatever long, medium or short branches, and that of 'Cui Guan' and 'Chang Li No.1' were equivalent; (4) In the number of inflorescence per plant, 'Yuan Huang' was the most up to 81 clusters, 'Cui Guan' was middle about 48 clusters, 'Chang Li No.1' was the least only 28 clusters; in the number of inflorescence flowers aspect, 'Chang Li No.1' was the largest about 9, 'Yuan Huang' and 'Cui Guan' were equal only 7; (5) In phenological period, 'Cui Guan' and 'Chang Li No.1' were similar, 'Yuan Huang' was about 5 days later than that of 'Cui Guan' and 'Chang Li No.1', and their fruit maturity was about 10 days different each other; (6)In damage by insects expression, 'Yuan Huang' was the lightest, next to 'Cui Guan', 'Chang Li No.1' was the most serious. Thus it could be seen, 'Yuan Huang' had the strongest adaptability in Hubei province, and 'Chang Li No.1' had the weakest adaptability in Hubei province of China.

\section{Introduction}

'Cui Guan' pear was a precocious variety bred by the Horticultural Institute of Zhejiang Academy of Agricultural Sciences and
Hangzhou Fruit Tree Research Institute with 'Xin shui' and ('Hang Qing' $\times$ 'New Century') in 1979. It was named in 1997 and authorized by the Zhejiang Crop Variety Examination Committee in 1999 (Shi and 
Guo, 1999). After 5 years of cultural experiment and observation, it was showed that the growth potential of 'Cui Guan' pear was strong (Yan and Li, 2011), the shape of fruit was round and uniform, the peel was dark green and smooth (Xia et al., 2017), the fruit was large and had better uniformity (He, 1998), the flesh was tender and crisp and had superior quality. It had high yield and stable production and strong resistance, was a variety with good development prospects (Ran et al., 2015).

'Yuan Huang' pear was a medium and early maturity pear variety bred by the National Horticultural Research Institute of the Rural Development Administration of Korea. It was named in 1994 and introduced into China in 1998. It characterized early mature, high yield, good quality, large fruit and disease resistance powerful in the middle and lower reaches of the Yangtze River. In particular, it was superior to other varieties in fruit storage, branch opening and easy shaping, and was suitable for large-scale development in this region (Chen et al., 2009; Liu et al., 2006).

'Chang Li No.1' was a new variety with excellent quality, which was superior to 'Huang Hua' pear in comprehensive quality (Wang et al., 2012). Its branches grew erect, especially before large number of bear fruit, so it was easy to be strong upside and weak bellow.

Pear is the third largest fruit tree in China, second only to apples and oranges in area and yield. The previous research results showed that "Cui Guan" and "Yuan Huang" had good adaptability in the middle and lower reaches of the Yangtze River, and were the two main varieties of sandy pear promoted in the market in recent years. However, 'Chang Li No.1' is a new local variety in Jingzhou city. Therefore, this study investigated the main biological characteristics of the three varieties in the first and third year after planted, in order to provide a scientific basis for the promotion of the superior sand pear varieties in Jingzhou area.

\section{Materials and Methods}

The stock of the three sand pear varieties were all Dou Li (Pyrus calleryana Decne.), which were planted in the Agricultural Science and Technology Park of Yangtze University in Jingzhou High-tech Zone on February 26, 2016. The planted pear seedlings were all the bud seedlings, and the experimental soil was sandy loam. After transplanted, the conventional management was carried out, and the tree shape were all open-center system.

The experiments were conducted in the Agricultural Science and Technology Industrial Park of Yangtze University in Jingzhou City, Hubei Province. The growth characteristics, phenological period and adaptability of 'Yuan Huang', 'Cui Guan' and 'Chang Li No.1' were investigated. On October 27, 2016, the growth characteristics of the three varieties in the first year after planted were investigated, and the survival rates of plants and buds were investigated. On September 20, 2018, the growth characteristics of the three varieties were measured and investigated again. Five representative trees of each variety were selected to measure the trunk diameter, tree height, crown diameter, number of annual branches (long, medium and short branches), number of leaves, leaf length, leaf width, insect pests, color of old leaves, leaf size, leaf edge serrate, leaf tip, leaf base, leaf thickness and so on. On March 26, 2019, the flowering characteristics of 'Yuan Huang', 'Cui Guan' and 'Chang Li No.1' were investigated, including the number of flowers per plant and the number of flowers per inflorescence. The number of petals and stamens were measured, 
and the color of young leaves was observed. In addition, the main phenological periods of the three sand pear varieties were observed in 2018 and 2019, including bud stage, leaf developing stage, initial flowering stage, full flowering stage, final flowering stage, fruit ripening stage and deciduous stage.

Data were mean values of 5 repeats. Microsoft Excel and SAS software was used to conduct variance analysis and significance test.

\section{Results and Discussion}

\section{Growth performance of three sand pear} varieties in the first year after planted

As you could see from table 1, in terms of plant height, 'Yuan Huang' was the highest, reaching $164.4 \mathrm{~cm}$, and 'Cui Guan' was the lowest, reaching $116.4 \mathrm{~cm}$. The plant height of 'Yuan Huang' was significantly higher than that of 'Chang Li No. 1' and 'Cui Guan'. In terms of trunk roughness, 'Yuan Huang' was the largest, 'Cui Guan' was the second, 'Chang Li No.1' was the smallest and significantly lower than "Cui Guan" and "Yuan Huang". The internode length of 'Yuan Huang' was significantly longer than that of 'Chang $\mathrm{Li}$ No.1' and 'Cui Guan'. The number of leaves of 'Chang Li No. 1' was the least, which was significantly less than that of 'Cui Guan' and 'Yuan Huang', and only about half of them, which was mainly related to disease and insect damage and drought in autumn. There was no significant difference in leaf length among the three varieties. The leaves of 'Chang Li No.1' were the widest, significantly wider than that of 'Yuan Huang' and 'Cui Guan'. The leaves of 'Cui Guan' were narrow and long. The survival rate of 'Chang Li No. 1' was the highest, while that of 'Cui Guan' and 'Yuan Huang' were significantly lower than that of 'Chang $\mathrm{Li}$ No.1', which may be related to the fact that 'Chang Li No. 1' came from local, while 'Cui Guan' and 'Yuan Huang' came from outside.

\section{Comparison of tree size of three sand pear varieties in the third year after planted}

It could be seen from table 2 that the trunk roughness, plant height, east-west crown diameter and north-south crown diameter of 'Yuan Huang' were significantly larger than that of 'Cui Guan' and 'Chang Li No.1' in the third year after planted, but there was no significant difference between 'Cui Guan' and 'Chang Li No. 1'.

Comparison of leaf correlation characteristics of three sand pear varieties in the third year after planted

It could be seen from table 3 , in terms of the number of leaves, there were significant differences among 'Yuan Huang', 'Cui Guan' and 'Chang Li No.1'. The number of leaves of 'Yuan Huang' was the most, followed by 'Cui Guan', while the number of leaves of 'Chang Li No.1' was less than half of that of 'Yuan Huang'. In terms of leaf length, 'Cui Guan' had the longest leaf length, followed by 'Yuan Huang', and 'Chang Li No.1' had the shortest leaf length.

In terms of leaf width, 'Chang Li No.1' was the widest, followed by 'Yuan Huang', and 'Cui Guan' was the narrowest. In terms of leaf shape index, there were significant difference among the three sand varieties, the leaf shape index of 'Cui Guan' was the largest, followed by 'Yuan Huang', and 'Chang Li No.1' was the smallest.

These results indicated that the number of leaves of 'Yuang Huang' was the largest, the length of leaves of 'Cui Guan' was the longest, the width of leaves of 'Chang $\mathrm{Li}$ No.1' was the widest, and the shape index of leaves of 'Cui Guan' was the largest.

As could be seen still from Table 3, 'Yuan Huang', 'Cui Guan' and 'Chang Li No.1' had 
certain differences in leaf characteristics. In the serrate of the leaf margin, 'Yuan Huang' was a prickly serrate and 'Chang Li No.1' was single serrate, but 'Yuan Huang' was curved inward, while 'Chang Li No.1' was curved outward. In the leaf base, 'Yuan Huang' and 'Cui Guan' had similar leaf bases, which were round, while 'Chang Li No.1' inclined heartshaped leaf base. In terms of pest occurrence, 'Chang Li No. 1' had mostly serious pest and 'Yuan Huang' had relatively light pest, which showed that there were significant differences in leaf characteristics among the three varieties in Jingzhou high-tech zone.

\section{Comparison of the number of annual branches and flowers among three sand pear varieties}

As could be seen from table 4, in the number of annual long branches, 'Yuan Huang' was the most, 'Cui Guan' was the second and 'Chang Li No.1' was the least. In the number of annual short branches, there were significant differences between 'Yuan Huang', 'Cui Guan' and 'Chang Li No. 1', the short branches of 'Chang Li No. 1' had less than a third of 'Yuan Huang'. In the number of inflorescence per plant, There were significant differences among the three varieties.

The number of inflorescence per plant of 'Yuan Huang' was twice as much as that of 'Chang Li No.1'. In the number of flowers per inflorescence, there were no significant differences among the three varieties.

There were significantly difference in the number of stamens among the three varieties, 'Chang Li No.1' was the most, followed by 'Yuan Huang' and 'Cui Guan'. The results showed that the bearing capacity of 'Yuan Huang' was the strongest, followed by 'Cui Guan', and 'Chang Li No.1' was the weakest.

\section{Comparison of main phenological periods of three sand pear varieties}

The main phenological periods of the three sand pear varieties in 2018 and 2019 are shown in table 5. It was observed that the phenological period of 'Cui Guan' and 'Chang Li No.1' was similar, they bud on early March and developed their leaves and entered the first flowering stage on mid-March, bloomed on late March, and entered the final flowering on the end of March. But the phenological period of 'Yuan Huang' was about 5 days later than that of 'Cui Guan' and 'Chang Li No.1', it began to bud on the middle of March, entered the early flowering and full flowering stage on late March, then entered the final flowering stage on early April. The ripening period of the three varieties of pears were about 10 days apart, which of 'Cui Guan' was the earliest, ripening in mid-July, and which of 'Chang Li No.1' was the next, ripening on late July, and which of 'Yuan Huang' was the latest, ripening on early August.

The deciduous periods of the three sand pear varieties were similar, and all of their leaves were dropped at the end of November.

The existing research results showed that 'Cui Guan', 'Yuan Huang' and 'Chang Li No.1' were relatively good varieties in production at present, among which 'Cui Guan' and 'Yuan Huang' had been widely promoted in production (Deng et al.,2021, Luo et al., 2015). 'Chang Li No.1' was a relatively excellent new variety selected locally in Jingzhou, and its maturity period was between 'Cui Guan' and 'Yuan Huang'. Although its fruit surface had rust like 'Cui Guan', its appearance quality could be significantly improved by bagging (Wang et al., 2012), and its fruit could be stored at $4^{\circ} \mathrm{C}$ for about 1 month after picking (Wang et al., 2012). 
Table.1 Growth performance of the three sand pear varieties in the first year after planting

\begin{tabular}{|c|c|c|c|c|c|c|c|c|c|}
\hline $\begin{array}{c}\text { Variety } \\
\text { name }\end{array}$ & $\begin{array}{c}\text { Plant } \\
\text { height/cm }\end{array}$ & $\begin{array}{c}\text { Trunk } \\
\text { roughness/cm }\end{array}$ & $\begin{array}{c}\text { Internode } \\
\text { length/cm }\end{array}$ & $\begin{array}{c}\text { Leaf } \\
\text { number }\end{array}$ & $\begin{array}{c}\text { Length of } \\
\text { leaves/cm }\end{array}$ & $\begin{array}{c}\text { Leaf } \\
\text { width/cm }\end{array}$ & $\begin{array}{c}\text { Leaf } \\
\text { shape } \\
\text { index }\end{array}$ & $\begin{array}{c}\text { Plant rate } \\
\text { of } \\
\text { survival/\% }\end{array}$ & $\begin{array}{c}\text { Budder } \\
\text { rate of } \\
\text { survival/\% }\end{array}$ \\
\hline $\begin{array}{c}\text { 'Yuan } \\
\text { Huang' }\end{array}$ & $164.4 \pm 13.8 \mathrm{a}$ & $1.07 \pm 0.11 \mathrm{a}$ & $3.6 \pm 0.34 \mathrm{a}$ & $22.5 \pm 0.21 \mathrm{a}$ & $12.7 \pm 0.11 \mathrm{a}$ & $6.0 \pm 0.37 \mathrm{~b}$ & $2.12 \pm 0.18 \mathrm{~b}$ & $84.1 \pm 7.6 \mathrm{~b}$ & $62.1 \pm 5.3 \mathrm{~b}$ \\
$\begin{array}{c}\text { 'Cui } \\
\text { Guan' }\end{array}$ & $116.4 \pm 9.5 \mathrm{~b}$ & $1.05 \pm 0.09 \mathrm{a}$ & $3.3 \pm 0.33 \mathrm{~b}$ & $22.1 \pm 0.19 \mathrm{a}$ & $13.1 \pm 0.18 \mathrm{a}$ & $5.5 \pm 0.32 \mathrm{c}$ & $2.38 \pm 0.21 \mathrm{a}$ & $82.2 \pm 8.5 \mathrm{~b}$ & $64.9 \pm 6.2 \mathrm{~b}$ \\
\hline $\begin{array}{c}\text { 'Chang } \\
\mathrm{Li} \\
\text { No.1' }\end{array}$ & $119.3 \pm 10.2 \mathrm{~b}$ & $0.99 \pm 0.08 \mathrm{~b}$ & $3.3 \pm 0.29 \mathrm{~b}$ & $11.5 \pm 0.13 \mathrm{~b}$ & $12.5 \pm 0.19 \mathrm{a}$ & $6.8 \pm 0.38 \mathrm{a}$ & $1.84 \pm 0.15 \mathrm{c}$ & $96.1 \pm 8.8 \mathrm{a}$ & $82.4 \pm 6.8 \mathrm{a}$ \\
\hline
\end{tabular}

Different small letters after the data in the same column indicate that the difference is 0.05 significant level, the same bellow table 2, table 3 and table 4 .

Table.2 Comparison of tree size of the three sand pear varieties in the third year after planting

\begin{tabular}{|c|c|c|c|c|}
\hline $\begin{array}{c}\text { Variety } \\
\text { name }\end{array}$ & $\begin{array}{c}\text { Trunk } \\
\text { roughness/cm }\end{array}$ & $\begin{array}{c}\text { Plant } \\
\text { height/m }\end{array}$ & $\begin{array}{c}\text { East-west crown } \\
\text { diameter/m }\end{array}$ & $\begin{array}{c}\text { North-south crown } \\
\text { diameter/m }\end{array}$ \\
\hline $\begin{array}{c}\text { 'Yuang } \\
\text { Huang' }\end{array}$ & $4.32 \pm 0.43 \mathrm{a}$ & $3.46 \pm 0.23 \mathrm{a}$ & $1.67 \pm 0.11 \mathrm{a}$ & $1.42 \pm 0.06 \mathrm{a}$ \\
\hline $\begin{array}{c}\text { 'Cui Guan' } \\
\text { 'Changli }\end{array}$ & $3.72 \pm 0.33 \mathrm{~b}$ & $2.72 \pm 0.09 \mathrm{~b}$ & $1.18 \pm 0.22 \mathrm{~b}$ & $1.02 \pm 0.16 \mathrm{~b}$ \\
\hline No.1' & $3.80 \pm 0.24 \mathrm{~b}$ & $2.65 \pm 0.31 \mathrm{~b}$ & $0.99 \pm 0.06 \mathrm{~b}$ & $1.03 \pm 0.12 \mathrm{~b}$ \\
\hline
\end{tabular}

Table.3 Comparison of leaf related characteristics of the three sand pear varieties in the third year after planted

\begin{tabular}{|c|c|c|c|c|c|c|c|c|c|c|c|}
\hline $\begin{array}{l}\text { Variety } \\
\text { name }\end{array}$ & $\begin{array}{c}\text { Leaf } \\
\text { number }\end{array}$ & $\begin{array}{c}\text { Leaf } \\
\text { length } \\
\text { /cm }\end{array}$ & $\begin{array}{c}\text { Leaf } \\
\text { width } \\
/ \mathrm{cm}\end{array}$ & $\begin{array}{l}\text { Leaf } \\
\text { shape } \\
\text { index }\end{array}$ & $\begin{array}{l}\text { Tender } \\
\text { leaf } \\
\text { color }\end{array}$ & $\begin{array}{l}\text { Old } \\
\text { leaf } \\
\text { color }\end{array}$ & $\begin{array}{c}\text { Leaf } \\
\text { margin }\end{array}$ & Leaf tip & Leaf base & $\begin{array}{c}\text { Leaf } \\
\text { thickness }\end{array}$ & $\begin{array}{c}\text { Insect } \\
\text { pest }\end{array}$ \\
\hline $\begin{array}{l}\text { 'Yuan } \\
\text { Huang', }\end{array}$ & $\begin{array}{c}494.4 \pm 50 \\
01 \mathrm{a}\end{array}$ & $\begin{array}{l}12.06 \pm \\
0.69 \mathrm{ab}\end{array}$ & $\begin{array}{l}7.10 \pm \\
0.8 \mathrm{ab}\end{array}$ & $\begin{array}{l}1.71 \pm \\
0.12 b\end{array}$ & deepred & kelly & $\begin{array}{l}\text { prickly } \\
\text { serrate }\end{array}$ & taper & roundness & thin & serious \\
\hline $\begin{array}{l}\text { 'Cui } \\
\text { Guan', }\end{array}$ & $\begin{array}{c}321.4 \pm 53 \\
53 \mathrm{~b}\end{array}$ & $\begin{array}{c}12.68 \pm \\
1.68 \mathrm{a}\end{array}$ & $\begin{array}{l}6.32 \pm \\
0.65 b\end{array}$ & $\begin{array}{c}2.01 \pm \\
0.2 \mathrm{a}\end{array}$ & darkred & $\begin{array}{c}\text { Dark } \\
\text { yellow }\end{array}$ & $\begin{array}{c}\text { single } \\
\text { serrated } \\
\text { tooth } \\
\text { bending } \\
\text { inwards }\end{array}$ & $\begin{array}{l}\text { long } \\
\text { anxious } \\
\text { tip }\end{array}$ & roundness & more thin & $\begin{array}{l}\text { more } \\
\text { serious }\end{array}$ \\
\hline $\begin{array}{l}\text { 'Chang } \\
\text { Li No.1' }\end{array}$ & $\begin{array}{c}231.4 \pm 17 \\
17 \mathrm{c}\end{array}$ & $\begin{array}{c}10.61 \pm \\
1.19 b\end{array}$ & $\begin{array}{l}7.44 \pm \\
0.68 \mathrm{a}\end{array}$ & $\begin{array}{c}1.43 \pm \\
0.2 \mathrm{c}\end{array}$ & $\begin{array}{l}\text { Shallow } \\
\text { darkred }\end{array}$ & $\begin{array}{c}\text { green } \\
\text { with } \\
\text { dark } \\
\text { yellow }\end{array}$ & $\begin{array}{l}\text { single } \\
\text { serrated } \\
\text { tooth } \\
\text { curved } \\
\text { outward }\end{array}$ & taper & $\begin{array}{l}\text { inclined } \\
\text { heart- } \\
\text { shaped }\end{array}$ & thickness & $\begin{array}{l}\text { mostly } \\
\text { serious }\end{array}$ \\
\hline
\end{tabular}


Table.4 Comparison of number of annual branches and flowers among three sand pear varieties

\begin{tabular}{|c|c|c|c|c|c|c|}
\hline $\begin{array}{c}\text { Variety } \\
\text { name }\end{array}$ & $\begin{array}{c}\text { Number of } \\
\text { annual long } \\
\text { branches }\end{array}$ & $\begin{array}{c}\text { Number of } \\
\text { annual middle } \\
\text { branches }\end{array}$ & $\begin{array}{c}\text { Number of } \\
\text { annual short } \\
\text { branches }\end{array}$ & $\begin{array}{c}\text { Number of } \\
\text { inflorescence } \\
\text { per plant }\end{array}$ & $\begin{array}{c}\text { Number of } \\
\text { flowers per } \\
\text { inflorescence }\end{array}$ & $\begin{array}{c}\text { Number of } \\
\text { stamens }\end{array}$ \\
\hline $\begin{array}{c}\text { 'Yuan } \\
\text { Huang' }\end{array}$ & $29.4 \pm 7.21 \mathrm{a}$ & $8.2 \pm 1.92 \mathrm{a}$ & $105.2 \pm 16.69 \mathrm{a}$ & $81.4 \pm 41.05 \mathrm{a}$ & $6.6 \pm 0.55 \mathrm{a}$ & $23 \pm 2.35 \mathrm{ab}$ \\
\hline $\begin{array}{c}\text { 'Cui } \\
\text { Guan' }\end{array}$ & $14.5 \pm 2.01 \mathrm{~b}$ & $5.8 \pm 2.49 \mathrm{ab}$ & $38.6 \pm 7.11 \mathrm{~b}$ & $48.4 \pm 15.69 \mathrm{ab}$ & $6.2 \pm 1.64 \mathrm{a}$ & $21.8 \pm 2.39 \mathrm{~b}$ \\
\hline $\begin{array}{c}\text { 'Chang } \\
\text { Li No.1' }\end{array}$ & $12.8 \pm 1.41 \mathrm{~b}$ & $3.4 \pm 1.14 \mathrm{~b}$ & $28.6 \pm 4.51 \mathrm{c}$ & $27.8 \pm 7.16 \mathrm{~b}$ & $7.8 \pm 0.84 \mathrm{a}$ & $26.4 \pm 4.04 \mathrm{a}$ \\
\hline
\end{tabular}

Table.5 Comparison of main phenological periods of the three sand pear varieties

\begin{tabular}{|c|c|c|c|c|c|c|c|c|}
\hline $\begin{array}{c}\text { Variety } \\
\text { name }\end{array}$ & Year & $\begin{array}{c}\text { Germinati } \\
\text { on stage } \\
\text { /month- } \\
\text { day }\end{array}$ & $\begin{array}{c}\text { Exhibition } \\
\text { leaf stage/ } \\
\text { month-day }\end{array}$ & $\begin{array}{c}\text { Initial } \\
\text { flowering } \\
\text { stage/ } \\
\text { month-day }\end{array}$ & $\begin{array}{c}\text { Full- } \\
\text { bloom stage/ } \\
\text { month-day }\end{array}$ & $\begin{array}{c}\text { Final } \\
\text { flowering } \\
\text { stage/ } \\
\text { month-day }\end{array}$ & $\begin{array}{c}\text { Fructescence } \\
\text { /month-day }\end{array}$ & $\begin{array}{c}\text { Leaf fall } \\
\text { period/ } \\
\text { month-day }\end{array}$ \\
\hline 'Yuang & 2018 & $3-13$ & $3-18$ & $3-22$ & $3-29$ & $4-3$ & $8-8$ & $11-28$ \\
huang' & 2019 & $3-10$ & $3-15$ & $3-18$ & $3-26$ & $4-1$ & $8-5$ & $11-25$ \\
\hline 'Cui & 2018 & $3-9$ & $3-13$ & $3-17$ & $3-22$ & $3-29$ & $7-16$ & $12-3$ \\
guan' & 2019 & $3-6$ & $3-10$ & $3-15$ & $3-20$ & $3-28$ & $7-14$ & $11-30$ \\
\hline 'Changli & 2018 & $3-8$ & $3-12$ & $3-16$ & $3-22$ & $3-27$ & $7-28$ & $11-29$ \\
\hline No.1' & 2019 & $3-4$ & $3-9$ & $3-13$ & $3-19$ & $3-25$ & $7-25$ & $11-26$ \\
\hline
\end{tabular}

The fruit ripening period of the three varieties was different. In Jingzhou area, the fruit ripening period of 'Cui Guan', 'Yuan Huang' and 'Chang Li No.1' were mid-July, early August and late July, respectively. The comparison of their fruit quality, storage performance and market benefit analysis needed to be further studied.

Through the investigation of the growth performance of 'Cui Guan', 'Yuan Huang' and 'Chang Li No.1' in the first and third year after planted in Jingzhou High-tech Zone, preliminary conclusions could be drawn as follows: The planted performance of 'Yuan Huang' pear in Jingzhou High-tech Zone was better than that of 'Cui Guan' and 'Chang Li No.1'. It was the strongest in the growth potential, the number of branches and the number of flowers per plant. Therefore, it was necessary to take measures such as pulling branches and twisted shoots to ease its growth potential and thinning flowers and fruits to improve the commercial quality of fruit.

The performance of 'Cui Guan' pear in Jingzhou High-tech Zone was in the middle, its resistance to diseases and insect pests was weak, but the fruit setting rate was the highest. According to the observation of the author, the ability of continuous bear fruit was also very strong. In the production, attention should be paid to the prevention of diseases and insect pests and the thinning of flowers and fruits.

'Chang Li No.1', as a native variety bred in Jingzhou, had strong upright branches and weak resistance to pests and diseases. In production, we should pay attention to strengthen the prevention and control of diseases and insect pests, and increase the application of organic fertilizer and protect its fruits and flowers. 


\section{References}

Shi, Zebin., Guo, Xingang. 1999. The breeding of early ripening pear variety 'Cuiguan' and its application. Acta Agriculturae Zhejiangensis, 11(4): 212-214.

Yan Sufen, Li Xiaogang. Introduction test of 6 high quality pear varieties including 'Cuiguan' in northern Jiangsu[J]. Chinese Horticulture Abstracts, 2011,27(5):24-25

Xia Chengxiang. Development prospect and key cultivation techniques of 'Cuiguan' pear[J]. Chinese Horticulture Abstracts, 2017,33(4):198-199

Hekun, Hong Linfang, Chen Fulong. Earlymaturing and high-quality cultivation technique of 'Cuiguan' pear[J]. Zhejiang Citrus, 1998,15(1):39-40

Ran Kun, Zhang Guiyao, Wang Hongwei, etc. Introduction and high yield cultivation techniques of 'Cuiguan' pear[J]. Deciduous Fruits, 2015,47(2):29-31

Chen Qiliang, $\mathrm{Hu}$ Hongju, Tian Rui, ect. Introduction performance and cultivation techniques of Korean 'Yuanhuang' pear in Wuhan[J]. Fujian Fruits, 2009,37(4):54-55

Liu Guangqin, Yin Mengbin, Shi Zhiyong.
Comprehensive performance and cultivation techniques of 'Yuanhuang' pear in middle and lower Yangtze River $[\mathrm{J}]$. South China Fruits, 2006,35(5):50-51

Wang Guiyuan, Xu Feng, Wang Piao, etc. Comparison of main biological characters and fruit quality of 'Jingli No.1' and 'Huanghua' pear varieties[J]. Jiangsu Agricultural Science, 2012,40(6):128-130

Deng Junbo, Huang Changwu, Liu Daoxian, etc. Characteristics of 'Cuiguan' pear and cultivation techniques of early fruit and high yield[J]. Deciduous Fruits, 2021,53(2):62-65

Luo Wei, Wang Keyou, Wang Zhaogang. Introduction and cultivation techniques of 'Yuanhuang' pear in Hanshui Basin[J]. Xiandai Horticulture, 2015,9:51-52

Wang Guiyuan, Xu Feng, Wang Piao, etc. Effects of bagging on fruit quality of 'Jingli No.1' pear[J]. Guangdong Agricultural Science, 2012,39(10):5152,76

Wang Guiyuan, Xu Feng, Li Jiao, etc. Effect of low temperature storage on fruit quality of 'Jingli No.1' pear. Guizhou Agricultural Science, 2012,40(5):166168

\section{How to cite this article:}

Tian-zhi Gong, Feng Xu and Guiyuan Wang. 2021. Comparison of Major Biological Characteristics and Adaptations of Three Sand Pear Varieties in Hubei Province of China. Int.J.Curr.Microbiol.App.Sci. 10(09): 441-447. doi: https://doi.org/10.20546/ijcmas.2021.1009.051 